\title{
O TEMA CARBOIDRATOS ATRAVÉS DA METODOLOGIA DE ESTUDOS DE CASO: DESENVOLVIMENTO DE CONTEÚDOS CONCEITUAIS, PROCEDIMENTAIS E ATITUDINAIS
}

\author{
Kamila dos Passos ${ }^{\mathrm{a}}$, Leandra F. Campo ${ }^{\mathrm{a}}$, Daniele P. Daniel ${ }^{\mathrm{b}}$, Franciane S. C. de Lima ${ }^{\mathrm{b}}$ Camila G. Passos ${ }^{\mathrm{b}, *}$ \\ a'Departamento de Química Orgânica, Instituto de Química, Universidade Federal do Rio Grande do Sul, 91501-970 Porto Alegre \\ - RS, Brasil \\ bDepartamento de Química Inorgânica, Instituto de Química, Universidade Federal do Rio Grande do Sul, 91501-970 Porto \\ Alegre - RS, Brasil
}

Recebido em 11/04/2018; aceito em 02/07/2018; publicado na web em 23/07/2018

\begin{abstract}
THE CARBOHYDRATE THEME THROUGH THE METHODOLOGY OF CASE STUDIES: DEVELOPMENT OF CONCEPTUAL, PROCEDURAL AND ATTITUDAL CONTENTS. This study aimed to analyze the contribution of the methodology of Case Studies to the development of conceptual, procedural and attitudinal contents inherent to the future professionals of Chemistry. In this sense, Cases on Carbohydrate Chemistry were elaborated to be solved by the students who studied the discipline of Organic Chemistry of Biomolecules of UFRGS. This research has a qualitative nature and it is a Case Study. For the data collection we used the Field Diary where the events were recorded along the activities developed through Participant Observation, audio recordings and the material produced by the participants as reports and presentations. In order to understand the students' perceptions about the activities, we used questionnaires with open questions and likert type. For the analysis of the data obtained were analyzed through coding categories, these elaborated using the guidelines of Bogdan and Biklen. According to the data analysis, the teaching methodology contributed to the development of knowledge related to the conceptual contents of carbohydrates, procedural contents such as oral and written argumentation, and attitudinal contents such as the investigative spirit.
\end{abstract}

Keywords: case studies; carbohydrate teaching; professional development; undergraduate chemistry teaching.

\section{INTRODUÇÃO}

A formação de profissionais empreendedores, capazes de superar os desafios da sociedade contemporânea, passa pela consolidação de conhecimentos que vão além dos específicos de uma área, como a Química, por exemplo. ${ }^{1-3}$ Nos dias de hoje, os químicos precisam de vivências formativas de perspectiva interdisciplinar e que lhes permitam uma visão mais geral do espaço em que sua atividade se insere na sociedade. ${ }^{2}$

Segundo relatos na literatura, ${ }^{1-3}$ algumas lacunas na formação dos químicos referem-se, principalmente, ao conhecimento de normas técnicas e da legislação sobre a produção de insumos, à propriedade intelectual e questões ambientais, assim como à capacidade de desenvolvimento autônomo desses indivíduos. Convergindo a esta compreensão, as Diretrizes Curriculares Nacionais para os Cursos de Química (DCNQ), estabelecidas pela Resolução 8/2002, ${ }^{4}$ a partir do Parecer 1.303/2001, ${ }^{5}$ definem que os profissionais da Química, tanto bacharéis quanto licenciados, deverão ter uma formação generalista, mas sólida de conhecimentos químicos e de áreas afins. Além disso, as DCNQ apontam para a necessidade de desenvolvimento de ações formativas que englobem conteúdos procedimentais e atitudinais, privilegiando o papel do estudante no processo de aprendizagem, formando um ser crítico capaz de refletir sobre sua função na sociedade. ${ }^{4}$

A partir de tais princípios e demandas, em 2005 a Universidade Federal do Rio Grande do Sul (UFRGS) reformulou e reestruturou os currículos dos cursos de Química. Ao analisar os diferentes cursos de Química oferecidos pela UFRGS (Bacharelado, Licenciatura e Industrial), foi possível constatar que estes possuem características comuns. Algumas disciplinas são as mesmas, principalmente aquelas voltadas aos conhecimentos de Química e áreas afins. Este é caso da disciplina de Química Orgânica de Biomoléculas, uma disciplina

*e-mail: camila.passos@ufrgs.br específica oferecida em caráter obrigatório aos cursos de Bacharelado e de Licenciatura, e que visa a "compreensão dos conceitos e leis da Química, o acompanhamento e compreensão dos avanços científicos e tecnológicos no campo da Química, inclusive seus aspectos interdisciplinares" (p. 15) ${ }^{6,7}$

Neste contexto, a docente regente desta disciplina até 2016, e orientadora deste trabalho, utilizava, entre outras, da metodologia de ensino de Estudos de Caso (EC) ${ }^{8}$ para atingir tais objetivos. De acordo com Sá e Queiroz, ${ }^{8}$ este é um método que oportuniza maior autonomia aos estudantes, pois estes vivenciam atividades que simulam situações similares às que poderão enfrentar no seu futuro profissional, proporcionando-lhes o contato com a investigação de aspectos científicos e sociocientíficos através de estudos em grupos ou individualizados. Essa abordagem de ensino estimula o desenvolvimento não apenas dos conteúdos conceituais envolvidos nas disciplinas em que é empregada, mas também de conteúdos procedimentais e atitudinais. ${ }^{1,9,10}$

Segundo Zabala, ${ }^{11}$ os conteúdos são os saberes que devem-se aprender para alcançar um objetivo, e incluem não apenas as capacidades cognitivas, mas as demais capacidades que envolvem um conjunto de hábitos e atitudes, organizados pedagógica e didaticamente. Nessa perspectiva, para Coll e colaboradores ${ }^{12}$ (apud Zabala), ${ }^{11}$ os conteúdos conceituais envolvem o conhecimento de fatos, fenômenos, princípios e leis, enquanto que os conteúdos procedimentais abrangem o saber fazer, o domínio das habilidades. Por fim, os atitudinais compreendem o saber ser, o envolvimento, o interesse, a postura e as vontades dos estudantes.

Neste âmbito, esta pesquisa buscou compreender quais as formas de contribuição da metodologia de EC com o tema "Química dos Carboidratos" para o desenvolvimento de conteúdos conceituais, procedimentais e atitudinais.

\section{ESTUDOS DE CASO}

Segundo pesquisas realizadas por Sá e Queiroz, ${ }^{8}$ os Estudos de 
Caso podem ser compreendidos como uma perspectiva de ensino desenvolvida a partir do método da Aprendizagem Baseada em Problemas (Problem Based Learning - PBL). Esse método de ensino foi implantado na década de 1960 na Faculdade de Medicina da Universidade McMaster, Canadá, para superar lacunas formativas quanto à integração de conhecimentos teóricos e práticos, e ainda possibilitar aos estudantes o contato com situações reais de sua futura prática profissional. Nesse sentido, mostrou-se tão eficiente que foi disseminado para outras universidades e cursos de diferentes áreas do conhecimento. ${ }^{8}$

No PBL, e suas variações, os estudantes devem identificar e definir problemas, avaliar informações necessárias para resolvê-los e defender uma solução para tais. Assim, o desenvolvimento de habilidades para a tomada de decisão a partir de problemas reais pode ser considerado o grande diferencial da utilização de casos. ${ }^{9}$ Convergindo a este viés de pensamento, os primeiros relatos do uso de casos no ensino de Química datam da década de $1990 .{ }^{13}$ Estes trabalhos tratam tanto sobre a aprendizagem dos conhecimentos científicos da Ciência, quanto o desenvolvimento de competências relacionadas ao exercício das possíveis áreas de atuação profissional. ${ }^{1}$

Normalmente, a metodologia de EC utiliza uma narrativa que conta um dilema ou um problema a ser resolvido ou avaliado, ou ainda pode retratar um caso histórico. ${ }^{13}$ Ao lerem os casos, os estudantes devem identificar e definir sua tarefa, formular hipóteses sobre sua resolução e desenvolver uma investigação sob a orientação do professor. Portanto, é importante que a estória seja de interesse dos estudantes, que contemple os conteúdos a serem desenvolvidos em uma determinada disciplina e que apresente situações que aproximem o discente de seu futuro profissional.

A metodologia faz com que o próprio estudante direcione a construção do seu conhecimento ${ }^{10}$ pois, ao receber o caso ofertado pelo docente, ele deve identificar o problema e buscar suas possíveis soluções ou explicações. Nesse sentido, durante a resolução dos casos o "papel principal do professor consiste em ajudar o estudante a trabalhar com os fatos e a análise de um problema a considerar, então, as possíveis soluções e consequências de suas ações" (p. 731). ${ }^{9}$ Assim, evidencia-se que essa metodologia centraliza o aprendizado no estudante e o professor passa a ser um orientador do processo investigativo, direcionando o estudante em sua formação.

Nessa perspectiva, Herreid relata que, ao contrário das aulas tradicionais que se concentram em fatos e conteúdos, esse método favorece o desenvolvimento de Habilidades de Ordem Superior como o "desenvolvimento analítico e a tomada de decisão, aprender a lidar com problemas da vida real, a comunicação oral e escrita, e, trabalho em grupo" (p. 222, tradução nossa). ${ }^{13}$ O método também visa o estimulo ao trabalho colaborativo através da discussão de dados e hipóteses dentro de pequenos grupos, ou com a turma, e assim auxilia no aprendizado do trabalho em grupo, fato que é corroborado pelos estudos de Belt e Cornely. ${ }^{1,10}$ As principais Habilidades de Ordem Superior aprimoradas ou adquiridas com a metodologia são: a identificação de questões-chave e de informações relevantes para a resolução dos casos, pois nessa atividade é a partir da investigação dos fatos apresentados no caso que o estudante poderá chegar a uma conclusão sobre o problema ou dilema apresentado. ${ }^{8,14}$ Dessa forma, a metodologia, como na vida real, não indica um único caminho a seguir nem mesmo impõe uma única resposta correta.

Com essas premissas, considera-se que as Habilidades de Ordem Superior desenvolvidas com a metodologia de EC podem ser divididas entre os três tipos de conteúdos classificados por Coll ${ }^{12}$ como conceituais, procedimentais e atitudinais. As Habilidades de Ordem Superior relatadas pelos autores que englobam os conteúdos procedimentais podem ser: a capacidade de executar tarefas de comunicação oral e escrita, a capacidade analítica na identificação de questões-chave, e a manipulação e leitura de diferentes fontes de referências. Já as que envolvem o trabalho em grupo, a tomada de decisão, a criticidade e o saber lidar com problemas da vida real podem se enquadrar dentro dos conteúdos atitudinais.

Segundo Cheng ${ }^{15}$ o método de EC pode contribuir para o desenvolvimento dos graduandos, porém tem-se que ter cuidado na implementação com estudantes imaturos e passivos, pois estes tendem a resistir às novas formas de aprendizado, apresentando dificuldades em formular opiniões, de modo que exigem a supervisão dos professores. Quanto às dificuldades apresentadas por Cheng, ${ }^{15}$ Belt ${ }^{1}$ destaca a importância de cativar os estudantes com a atividade desde o início, para que compreendam os princípios da metodologia e não se sintam frustrados ao perceberem que na maioria das vezes não haverá apenas uma resposta correta. Sá e Queiroz ${ }^{8}$ sugerem uma breve apresentação da metodologia aos estudantes para que estes entendam as atividades propostas. Heirred ${ }^{13}$ relata que professores e estudantes devem ter contato com o método com maior frequência para que fiquem confortáveis em seu emprego. A metodologia pode ser utilizada em uma gama de situações e para trabalhar diversos conteúdos, mas também é salientado por Heirred ${ }^{13}$ que a metodologia não favorece explorar e aprofundar tantos conceitos quanto às aulas expositivas. Logo, a eficácia da metodologia quanto ao desenvolvimento dos conteúdos conceituais pode ser atribuída ao caso em si.

\section{O emprego da metodologia no Brasil}

Conforme os dados levantados para esta pesquisa, os primeiros relatos da utilização de EC no ensino superior em Química no Brasil são dois artigos publicados no periódico Química Nova de 2007. O primeiro artigo é de autoria de Luciana Passos Sá, Cristiane Andretta Francisco e Salete Linhares Queiroz sob o título "Estudos de Caso em Química". ${ }^{16} \mathrm{O}$ segundo artigo publicado nesse ano é de autoria de Luciana Passos Sá e Salete Linhares Queiroz intitulado "Promovendo a argumentação no Ensino superior em Química". 9

Considerando estes dois trabalhos publicados em 2007 como o marco do início da divulgação sobre a utilização deste método de ensino em disciplinas de cursos de graduação em Química no Brasil, realizou-se uma pesquisa a fim de identificar os direcionamentos do uso da metodologia de EC no ensino superior em Química no país. Para tal, concentrou-se a atenção na revista Química Nova e em alguns dos principais periódicos de Qualis A1, A2 e B1, na área de Ensino, segundo a classificação da CAPES (Coordenação de Aperfeiçoamento de Pessoal de Nível Superior). Buscou-se artigos publicados entre os anos de 2008 e 2017, utilizando-se "estudos de caso" como palavra-chave. Os resultados obtidos estão apresentados na Tabela 1.

Os artigos selecionados foram analisados quanto aos objetivos do estudo, às formas de trabalho adotadas (grupo ou individual), à apresentação das resoluções dos casos (produção textual, plenária, etc), às habilidades desenvolvidas e às dificuldades encontradas no emprego da metodologia proposta.

A partir desse quadro é possível perceber que os EC podem ser empregados à formação de diferentes profissionais, objetivos de pesquisa e conteúdos. Com isso, destaca-se a versatilidade do método.

Nos artigos enumerados na Tabela 1 como 1,4 e 5 , voltados à formação de professores de Química, entre os principais objetivos destacados está a capacitação destes estudantes para o uso da metodologia. De acordo com Massena e colaboradores, ${ }^{21}$ os professores apresentam dificuldades em trabalhar com os EC por não possuírem a devida formação. Resultado que vai ao encontro das ideias de Pinheiro e colaboradores,${ }^{20}$ ao trazerem a compreensão de que os estudantes de licenciatura, em sua formação acadêmica, possuem uma vivência muito diferente daquela que irão encontrar em sua vida profissional e, portanto, é necessário não só apresentar a metodologia aos discentes, 
Tabela 1. Principais dados dos artigos analisados

\begin{tabular}{|c|c|c|c|c|}
\hline Artigo & Periódico & Data & Curso & Conteúdo \\
\hline $\begin{array}{l}\text { Aprendizagem Baseada em Casos Investigativos e a } \\
\text { 1. formação de professores: o potencial de uma aula prática } \\
\text { de volumetria para promover o ensino interdisciplinar }{ }^{17}\end{array}$ & QNESC & 2014 & Formação de Professores & $\begin{array}{l}\text { Metodologias ativas de } \\
\text { ensino }\end{array}$ \\
\hline $\begin{array}{l}\text { Argumentação de graduandos em Química sobre } \\
\text { 2. questões sociocientíficas em um ambiente virtual de } \\
\text { aprendizagem }{ }^{18}\end{array}$ & QNESC & 2015 & Química Bacharelado & $\begin{array}{l}\text { Comunicação, expressão e } \\
\text { linguagem científica }\end{array}$ \\
\hline 3. Resenha: Estudos de Caso para o Ensino de Química $1^{19}$ & QNESC & 2017 & - & - \\
\hline 4. Estudo de casos na formação de professores de Química ${ }^{20}$ & Química Nova & 2010 & Química Licenciatura & Físico-Química \\
\hline $\begin{array}{l}\text { 5. Produção de casos para o ensino de Química: uma expe- } \\
\text { riência na formação inicial de professores }{ }^{21}\end{array}$ & Química Nova & 2013 & Química Licenciatura & Química Inorgânica \\
\hline $\begin{array}{l}\text { 6. Casos investigativos para a promoção da CSCL no ensino } \\
\text { superior de Química }^{22}\end{array}$ & Química Nova & 2017 & Química Bacharelado & Aprendizagem colaborativa \\
\hline 7. Resenha: Estudo de caso no ensino de Química ${ }^{23}$ & Ensaio & 2010 & - & - \\
\hline $\begin{array}{l}\text { El uso de un caso de investigación para el estudio de los } \\
\text { 8. métodos electrolíticos: una experiencia en la Educación } \\
\text { superior }^{24}\end{array}$ & REEC & 2013 & $\begin{array}{l}\text { Engenharia de } \\
\text { Bioprocessos e } \\
\text { Biotecnologia }\end{array}$ & Química Analítica \\
\hline $\begin{array}{l}\text { 9. Argumentos elaborados sobre o tema "corrosão" por } \\
\text { estudantes de um curso superior de Química }{ }^{25}\end{array}$ & REEC & 2009 & Química Bacharelado & $\begin{array}{c}\text { Comunicação, expressão e } \\
\text { linguagem científica }\end{array}$ \\
\hline $\begin{array}{l}\text { 10. Casos investigativos de caráter sociocientífico: aplicação } \\
\text { no ensino superior de Química }{ }^{26}\end{array}$ & Educación Química & 2013 & Química Bacharelado & $\begin{array}{l}\text { Comunicação, expressão e } \\
\text { linguagem científica }\end{array}$ \\
\hline
\end{tabular}

mas também demonstrar como desenvolvê-la em sala de aula e como elaborar os casos a serem utilizados. Tendo isso em vista, no artigo 5 , os estudantes foram estimulados a produzirem casos sobre os conteúdos abordados na disciplina em questão (Química Inorgânica). Com esta atividade, eles tiveram um contato maior com a sua futura prática profissional, o que lhes proporcionou perceber algumas das dificuldades que irão enfrentar como, por exemplo, a adequação de conteúdos ao ensino médio. Já nos artigos 1 e 4 a pesquisa foi direcionada à vivência dos estudantes com a metodologia, nesses estudos, os casos foram apresentados ao grupo de alunos e estes tiveram a tarefa de resolvê-los.

Os artigos 2, 6, 8, 9 e 10 - voltados a estudantes de bacharelado em Química - possuíam como principais objetivos a análise das habilidades desenvolvidas com a aplicação do método. Em 2, 9 e 10 os estudos estavam voltados para a habilidade de argumentação. Essa habilidade é destacada pelos pesquisadores como sendo de grande importância no aprendizado das Ciências, pois, conforme Souza e colaboradores, oportuniza aos alunos "alcançar um entendimento mais amplo e aprofundado sobre o tema em foco" (p. 96) ${ }^{18}$ quando lhes é estabelecida a necessidade de se posicionar sobre um tema e justificar esse posicionamento. Percebe-se que em nenhum dos artigos analisados foi apresentado uma avaliação da contribuição da metodologia para o desenvolvimento de conceitos químicos e que, em sua maioria, os casos foram empregados em disciplinas que estão relacionadas ao desenvolvimento de outras habilidades, como leitura, escrita e argumentação oral (artigo 6). Apenas três estudos foram realizados em disciplinas de conhecimentos específicos de Química.

Apesar de existirem várias formas de se trabalhar com EC, ${ }^{8,13}$ nos artigos analisados destacam-se o formato de trabalho em grupos ou em duplas, tanto para resolver os casos, quanto para elaborar as estórias..$^{18}$ Nestes exemplares, as turmas foram divididas e os casos distribuídos aleatoriamente para sua resolução. Mostrou-se como estratégia recorrente a utilização de uma plataforma digital, para favorecer as discussões entre os estudantes. ${ }^{18,22}$

A forma como as resoluções dos casos foram apresentadas tiveram algumas variantes, como no artigo 1 , no qual os estudantes deveriam resolver um caso sobre volumetria, o qual deveria ser discutido em grupo e as práticas efetuadas individualmente. Nos artigos 2 e 6, a resolução dos casos foi dividida em etapas: na primeira etapa os estudantes deveriam elaborar um texto de forma individual propondo uma solução para o seu caso. Após isso o professor selecionou duplas de trabalho de modo que as visões de seus componentes fossem opostas, para a resolução do problema e de forma colaborativa - através de uma plataforma digital - deveriam solucionar o problema. Numa seguinte etapa, os estudantes deveriam elaborar, novamente de forma individual, um texto com a sua resolução final sobre o caso. $\mathrm{O}$ artigo 4 demonstra uma maior preocupação em diagnosticar as dificuldades que professores de Química do ensino médio poderão enfrentar, tanto com relação aos seus conhecimentos sobre o tema, quanto com relação à infraestrutura de seu local de trabalho. No artigo 5, também voltado para a formação de professores de Química, os estudantes deveriam elaborar um Diário do Caso "este diário deveria deixar claro ao leitor o processo que conduzirá o grupo à resolução do caso, com reflexões acerca das atividades e arquivo de todo o material empregado como fonte de pesquisa" (p. 1067). ${ }^{21}$ Este recurso de produção textual também foi descrito no artigo 10, porém, nessa proposta o professor solicitou a produção textual individual. Para os estudantes que participaram da pesquisa relatada no artigo 8, foi solicitado que elaborassem um relatório do caso no qual deveria ser apresentada uma solução para o caso proposto e os conceitos científicos envolvidos no mesmo. A apresentação oral foi indicada como estratégia de exposição das soluções para os casos apenas no artigo 9.

Os pesquisadores apontam, de forma geral, que essa estratégia de ensino favorece o desenvolvimento da comunicação oral e escrita, a capacidade de resolver problemas reais e da capacidade de tomada de decisão. ${ }^{24-26}$ Conforme enfatiza Francisco, ${ }^{24}$ essa última habilidade (capacidade de tomada de decisão) é essencial para uma abordagem do ponto de vista da Ciência, Tecnologia e Sociedade, para contemplar uma sociedade mais democrática. $\mathrm{O}$ trabalho colaborativo ${ }^{22} \mathrm{ou}$ cooperativo $^{24-26}$ também foi destacado pelos autores como um ponto positivo da metodologia, pois a capacidade de trabalhar em grupo, a partir das discussões realizadas, propicia a construção do conhecimento. O método é apontado como adequado para desenvolver a argumentação $0^{18,22,25,26}$ dos estudantes, já que esta pode auxiliar os 
mesmos a compreenderem conceitos científicos de forma mais adequada, assim como a natureza da construção destes conhecimentos. Nos estudos realizados por Pierini e colaboradores, ${ }^{17}$ foram utilizados experimentos de laboratório como estratégias de investigação, para a resolução dos problemas, sendo possível constatar que essa é uma forma eficiente de relacionar a teoria com a prática. Estes pesquisadores também reforçam a ideia de que esta é uma prática de ensino que se adequa ao ensino interdisciplinar, já que problemas da vida real possuem uma dimensão ampla e exigem o conhecimento de diversas disciplinas para seu entendimento. ${ }^{17}$

Ainda que a maioria dos relatos afirme que a metodologia suscitou uma boa receptividade por parte dos estudantes, para o desenvolvimento das atividades propostas, eles também sugerem a necessidade de capacitar os professores para o emprego dessa metodologia. ${ }^{17,20,21}$ Os pesquisadores salientam que a aprendizagem colaborativa é mais favorecida quando os estudantes são mais participativos durante a discussão para a resolução dos casos. ${ }^{22}$ Apenas Pinheiro e colaboradore ${ }^{20}$ relataram haver uma certa resistência por parte dos licenciandos em discutir o tema proposto, o que foi atribuído à falta de conhecimento, interesse, ou por não fazer parte do cotidiano de escolas de educação básica. Dentre algumas dificuldades descritas estão a adequação de conteúdos ${ }^{10}$ quando a proposta foi elaborar o caso para utilização com estudantes do ensino médio, assim como a compreensão do tema proposto e a elaboração do diário do caso. ${ }^{21}$ Os autores inferem que estas dificuldades referem-se à pouca habilidade de escrita por parte dos estudantes, fato que também foi observado quanto à qualidade dos argumentos, mesmo que a metodologia tenha se prestado para fomentar a elaboração de argumentos, estes tiveram uma baixa qualidade. ${ }^{25}$

A partir desse levantamento é possível concluir que passados 10 anos dos primeiros estudos sobre a metodologia de EC, no ensino superior em Química no Brasil, seu uso ainda é restrito, visto o pequeno número de artigos localizados. Destaca-se a relevância de pesquisas sobre o tema, pois os EC favorecem o desenvolvimento de habilidades importantes aos profissionais da Química, como comunicação oral e escrita, visto que as metodologias tradicionais de ensino não estão direcionadas para o trabalho dos conteúdos procedimentais e atitudinais. Nesse sentido, este estudo visa auxiliar na difusão de mais uma experiência formativa no contexto do ensino superior de Química a partir dos EC. Além de divulgar que os professores podem acessar casos prontos, que podem ser aplicados em sala de aula, em livros publicados por pesquisadores da área, ${ }^{19}$ assim como contribuições sobre a origem e popularização do método. ${ }^{23}$

\section{METODOLOGIA DE PESQUISA}

No presente trabalho, optou-se pela pesquisa qualitativa, pois esta permite uma visão mais ampla de um cenário, transformando e construindo o conhecimento coletivo. Além disso, neste tipo de pesquisa o pesquisador participa do processo, descreve os significados, analisa a produção escrita por meio de interpretação e desenvolve a teoria, possibilitando narrativas ricas e interpretações individuais. ${ }^{27}$ Os objetivos de interesse na pesquisa qualitativa são amplos e partem de uma perspectiva diferenciada daquela adotada nos métodos quantitativos. A obtenção de dados descritivos é, principalmente, através de contato direto e interativo do pesquisador com a situação objeto de estudo. ${ }^{28}$ Para tanto, neste tipo de pesquisa, é habitual que o pesquisador trabalhe para entender os fenômenos, segundo a perspectiva dos participantes da situação objeto do estudo e, assim, possa estabelecer sua interpretação dos fenômenos estudados. ${ }^{29}$

Sendo esse estudo, portanto, qualitativo, optou-se por utilizar o método de pesquisa de Estudo de Caso. Conforme Merriam ${ }^{27}$ (apud Bogdan e Biklen), ${ }^{28}$ este método consiste na observação detalhada de um contexto, ou um indivíduo, de uma única fonte de documentos ou de um acontecimento, ou seja, é o estudo de um caso particular, conforme Ludke e André. ${ }^{29}$

Para a coleta dos dados, ao longo da pesquisa os estudantes responderam a questionários fornecidos pelas pesquisadoras. $\mathrm{O}$ Questionário Inicial possuía o intuito de diagnosticar o conhecimento prévio dos estudantes sobre carboidratos, a metodologia de EC, o perfil acadêmico e profissional dos estudantes. Para que os discentes avaliassem a metodologia de EC utilizada, estes responderam um Questionário Final de Avaliação das Atividades Desenvolvidas com escala Likert $^{30}$ adaptado de pesquisas anteriores, como os trabalhos de $\mathrm{Goi}^{31}$ e Sá. ${ }^{32}$ Esse instrumento era composto de uma pergunta com 10 afirmativas e duas questões abertas que foi distribuído aos estudantes no final da resolução do caso.

Os dados obtidos com o questionário com escala Likert foram analisados através da intepretação de gráficos. Estes gráficos foram obtidos através de uma renormalização de dados, sendo que a cada grau de concordância foi atribuído um valor, sendo -2 para Discordo fortemente, -1 para Discordo parcialmente, zero para Não tenho uma opinião formada, 1 para Concordo parcialmente e 2 para Concordo fortemente. O cálculo do valor de concordância foi determinado através do somatório do número de vezes em que a opção foi marcada, vezes a pontuação atribuída a ela e dividido pelo número total de respostas. Dessa forma construiu-se um gráfico para a avaliação do método de ensino quanto às formas de contribuição para o desenvolvimento de conhecimentos e habilidades.

Durante a pesquisa foram coletados dados através da Observação Participante, ${ }^{28}$ que foram registrados em um Diário de Campo. ${ }^{29}$ Também foram utilizadas como fontes de dados as gravações em áudio das apresentações das resoluções dos casos e as produções escritas (relatórios e apresentações) sobre os temas abordados nas atividades da pesquisa. Estes instrumentos foram empregados para a análise do desenvolvimento da metodologia, e para a compreensão do grau de apropriação de conceitos por parte dos estudantes, assim como para a identificação do desenvolvimento de habilidades relacionadas aos conteúdos procedimentais e atitudinais.

Os dados foram sistematizados e analisados através de categorias de codificação fundamentadas nas proposições de Bogdan e Biklen. ${ }^{28}$ As categorias elaboradas convergem aos objetivos da pesquisa quanto à análise do desenvolvimento ou aperfeiçoamento dos conteúdos conceituais, conteúdos procedimentais e conteúdos atitudinais.

\section{Implementação da metodologia para o estudo dos carboidratos}

O estudo foi realizado no semestre $2015 / 02$, com os nove estudantes que cursaram a disciplina de Orgânica de Biomoléculas. O método foi aplicado em quatro encontros, com um total de 8 horas-aula. Para tanto, inicialmente dois casos foram aperfeiçoados do material original utilizado em semestres anteriores pela professora regente da disciplina. Os referidos casos foram reescritos visando atender aos critérios destacados na literatura para a elaboração de um bom caso, segundo Heirred ${ }^{13}$ e Sá e Queiroz. ${ }^{9}$ Conforme estes autores, os casos, além de terem utilidade pedagógica, devem ser atuais e de relevância ao leitor, para que lhe despertem o interesse no estudo criando empatia com os personagens da estória narrada. Desta forma, estas estórias não podem ser muito longas para não se tornarem enfadonhas, e também devem incluir citações, apresentar generalizações e levar a uma situação conflituosa que force os estudantes a tomarem uma posição. Além disso, os casos continham questões norteadoras que tinham como objetivo o direcionamento do estudo dos grupos, de modo que tópicos importantes do conteúdo não fossem negligenciados ao resolver os casos. Os casos e as questões foram validados por dois especialistas da área de Ensino de Química 
e por dois especialistas de Química Orgânica, certificando quanto à adequação de linguagem, à estrutura e à natureza dos casos para abordar o tema carboidratos no Ensino Superior. Os casos e questões norteadoras constam no material suplementar.

Optou-se por uma estratégia de trabalho no formato de pequenos grupos, ${ }^{8}$ de modo que a turma, contendo nove estudantes, foi dividida em dois grupos e a estes foram distribuídos os casos de maneira aleatória. Na primeira aula foi realizada a apresentação da proposta metodológica, a discussão inicial sobre o tema dos casos, a organização dos grupos de trabalho, a distribuição dos casos e elaboração das hipóteses de resolução. No segundo encontro, os alunos realizaram a pesquisa bibliográfica no laboratório de informática e/ou na biblioteca, para fundamentar as hipóteses de resolução propostas. A terceira aula foi direcionada para a discussão interna nos grupos e com a professora, para orientação e reflexão sobre o processo de resolução dos casos, a elaboração do relatório escrito e da apresentação final. No último encontro, os alunos entregaram o relatório, apresentaram as resoluções no formato de uma plenária, para possibilitar a finalização da atividade com os apontamentos da professora, sobre as modelações de resoluções empregadas pelos grupos.

Os estudantes que receberam o Caso 1 deveriam se colocar como membros de uma comissão da Associação Brasileira de Saúde Coletiva (ABRASCO), para defender os interesses do órgão que representam e apresentar soluções plausíveis de serem adotadas pela indústria alimentícia, na busca de uma redução significativa da adição de açúcar em sucos naturais industrializados, visando a melhoria da qualidade de vida do consumidor. O outro grupo recebeu o Caso 2, no qual os estudantes que deveriam resolvê-lo estariam representando a indústria alimentícia e seus interesses. Portanto, esses estudantes formavam um grupo que foi contratado pela Associação Brasileira de Bebidas (ABRABE), e deveriam defender os interesses do órgão que representam e apresentar soluções plausíveis de serem adotadas pela indústria alimentícia, na busca de uma redução significativa da adição de açúcar em sucos naturais industrializados.

\section{RESULTADOS E DISCUSSÕES}

Para manter o sigilo da identidade dos sujeitos da pesquisa, esses foram chamados de E1, E2, E3, E4, E5, E6, E7, E8 e E9, sem distinção de gênero. Quanto à formação acadêmica, a turma contava com dois estudantes graduados em Química Industrial, sendo que um possuía também Tecnólogo em Gestão Ambiental e o outro estava cursando doutorado. Três eram técnicos em Química e os outros quatro não possuíam formação na área. Com vistas nessas informações, pode-se concluir que o grupo, ainda que diversificado, possuía um nível relativamente alto de conhecimento químico. Sobre a atuação profissional, o grupo era composto por seis bolsistas de Iniciação Científica que atuavam na área de pesquisa em Química, um bolsista de doutorado e dois trabalhando formalmente na indústria Química. Apenas um estudante apontou não trabalhar na área, apesar de ressaltar que atuava na área de Química Teórica, mas não especificou o tipo de trabalho.

Como a turma era composta por estudantes em final de curso, ou seja, já possuíam uma visão sobre a formação oferecida por sua graduação e, tendo em vista que todos possuíam algum tipo de experiência profissional (pesquisa ou indústria), considerou-se que os sujeitos estavam aptos para avaliar de que forma os conteúdos abordados na graduação se relacionam com os conhecimentos que eles julgam ser necessários para sua pretensa profissão.

\section{Conteúdos conceituais}

No Questionário Inicial os estudantes deveriam conceituar e apresentar exemplos de Carboidratos. Dos nove participantes da pesquisa, três alunos não souberam definir o que são carboidratos e nem citaram exemplos. Apenas dois apresentaram exemplos, porém sem atribuir um conceito. Quatro estudantes conseguiram apresentar um conceito convergente aos aportes da literatura, sendo que apenas um deles também apresentou exemplos, entre estes conceitos destaca-se os dos Estudantes 8 e 2, respectivamente:

\section{E8: Moléculas orgânicas responsáveis pelo fornecimento de energia ao organismo (através de reações). Em geral, são açúcares. \\ E2: Carboidratos são estruturas com fórmula estrutural $\mathrm{C}_{n}\left(\mathrm{H}_{2} \mathrm{O}\right)_{m}$. Ex. Manana, quitosana.}

Conforme Nelson e Cox, ${ }^{33}$ os carboidratos formam o grupo de biomoléculas mais abundantes do planeta e são a principal fonte de energia de seres vivos na forma de amido ou açúcar. Do ponto de vista químico, pode-se conceituar os carboidratos como poliidroxialdeídos (aldoses) ou poliidroxicetonas (cetoses), ou substâncias que quando hidrolisadas formam aldoses ou cetoses. Os carboidratos podem exibir estruturas em equilíbrio na forma acíclica ou cíclica e podem ser classificados em três grandes grupos: monossacarídeos, oligossacarídeos e polissacarídeos. Monossacarídeos: são constituídos por uma única unidade de poliidroxicetona ou poliixodrialdeído, ou seja, não podem ser hidrolisados a carboidratos mais simples. $\mathrm{O}$ monossacarídeo mais abundante é o D-glicose. Oligossacarídeos: são formados pela união de monossacarídeos através da ligação glicosídica, formando cadeias curtas. Os oligossacarídeos mais abundantes são os dissacarídeos, que surgem da união de dois monossacarídeos como, por exemplo, a sacarose que é formada pela união de uma D-frutose e uma D-glicose. A ligação glicosídica é formada quando um grupo hidroxila de um açúcar reage com o carbono anomérico de outro açúcar. Polissacarídeos: são polímeros com mais de 20 unidades de carboidratos, sendo a celulose e o glicogênio os exemplos mais importantes desta classe de carboidratos. ${ }^{33}$

Frente a este resultado, considerou-se necessário o aperfeiçoamento conceitual dos estudantes que participaram desta investigação quanto ao tema carboidratos, visto que apenas o Estudante 2 apresentou conceito e exemplos convergentes ao conceito científico dessas biomoléculas.

Com a análise das discussões realizadas durante as diferentes etapas do desenvolvimento das atividades, conforme apontamentos no Diário de Campo da pesquisadora e através dos relatórios escritos pelos grupos, foi possível perceber o desenvolvimento conceitual acerca de diversos aspectos da temática, como a estrutura, propriedades e metabolização de carboidratos e edulcorantes, assim como aspectos legais sobre bebidas.

De acordo com os apontamentos do Diário de Campo e da análise dos relatórios, o grupo responsável pela resolução do Caso 2 propôs, como hipótese de resolução para o referido caso, a redução gradativa do açúcar e ao mesmo tempo a adição de edulcorantes que compensassem a quantidade de açúcar que seria retirada dos sucos industrizados. Dessas substâncias, a estévia foi o principal edulcorante indicado por ser natural, embora o grupo tenha pensado na frutose também. Os estudantes não buscaram pelas estruturas dos açúcares, o que provalvelmente os levaram a relacionar açúcar apenas com sacarose, e não perceberam que a frutose também é um açúcar. Assim, o grupo concluiu parcialmente a resolução do caso, pois não buscou a diferenciação da estrutura química destes compostos.

Os açúcares possuem sabor doce. Esta propriedade está relacionada com a capacidade de formar ligações de hidrogênio com proteínas presentes nas papilas gustativas. ${ }^{34}$ Os principais açúcares utilizados para adoçar os alimentos são a glicose, a sacarose e a frutose. Estes são classificados em uma escala de doçura onde para a sacarose é 
atribuído valor 1,00. A glicose recebe valor 0,5, ou seja, adoça menos que a sacarose, e a frutose é considerada o açúcar mais doce, com valor de 1,73. Esse poder adoçante está relacionado com a capacidade de interação de cada estrutura. ${ }^{34}$

Tomando a substituição do açúcar pela estévia como a principal estratégia de trabalho, ao pesquisarem a legislação, os estudantes do grupo responsável pelo Caso 2 concluíram que esta não poderia ser aplicada, porque a estévia é considerada uma substância não calórica (não é metabolizada pelo organismo). Segundo a legislação que estava vigente até o momento do trabalho, não era permitido misturar substâncias não calóricas ou hipocalóricas com substâncias calóricas (Art. 14 do Decreto n ${ }^{\circ} 2.314$ ). ${ }^{35}$ Essa legislação foi modificada após o término desta investigação. ${ }^{36}$ Então, a conclusão do grupo foi a de sugerir apenas a diminuição gradual do açúcar, já que não há prazo para essa redução.

A percepção dos estudantes foi de que a bebida com menos açúcar teria o apelo comercial de ser mais saudável. Contudo, ao adicionar adoçantes essa característica poderia ser perdida, pois é senso comum que estes produtos não fazem bem à saúde humana.

Os estudantes fizeram uma significativa avaliação do caso, pois, segundo a literatura, o consumo do açúcar está associado ao desenvolvimento de diversas doenças. ${ }^{37,38}$ Porém, os estudos sobre a segurança do uso de edulcorantes são controversos ${ }^{39}$ e diante dessas incertezas a população pode não apreciar o consumo dessas substâncias, ainda que sejam aprovadas pelos órgãos de regulamentação como a Agência Nacional de Vigilância Sanitária (ANVISA). ${ }^{40} \mathrm{Os}$ estudantes também buscaram informações sobre a legislação que regulamenta a produção de bebidas industrializadas ${ }^{35}$ e $\operatorname{argumen-}^{-}$ taram sobre a necessidade de modificar a legislação, o que ocorreu após a finalização deste trabalho.

Já os integrantes do grupo responsável pela resolução do Caso 1 trouxeram informações que apontaram para o aprofundamento de seus estudos. Nos relatos descritos no Diário de Campo ficou evidente que os estudantes conseguiram compreender que os açúcares são os próprios carboidratos, ao destacarem, durante a plenária, que existem açúcares diferentes como a glicose e a frutose. Os estudantes ainda apresentaram dados sobre a estrutura dos carboidratos, porém, cometeram um pequeno equívoco na nomenclatura, ao dizerem que os monossacarídeos estão unidos por uma ligação "éter" ao invés de usar a denominação "ligação glicosídica", mais correta neste caso. ${ }^{33}$ Ademais, trouxeram informações sobre a atuação dos açúcares no organismo, ao citarem que a frutose compromete a supressão da grelina, hormônio que estimula a fome, ou seja, a frutose não permite que ao consumir alimentos que contenham frutose cesse a liberação desse hormônio. ${ }^{38}$ Destacaram também a importância de se adicionar açúcares nos sucos para sua conservação. A propriedade conservante do açúcar se deve à redução da atividade da água (esta é uma medida utilizada para expressar a disponibilidade de água). Como o crescimento e o metabolismo dos microorganismos demanda a presença de água em forma disponível, ao aumentar a concentração do soluto na fase aquosa do alimento reduz-se a atividade da água. ${ }^{33}$

Para aprofundar a análise apresentada, as questões abertas do Questionário de Avaliação das Atividades Desenvolvidas foram utilizadas para relacionar a avaliação sobre o desenvolvimento de conteúdos conceituais, com a análise dos registros do Diário de Campo, relatórios e apresentações dos estudantes.

Ao serem questionados se a metodologia utilizada favoreceu o aprendizado ou o aprofundamento de conceitos, a maioria respondeu afirmativamente. Apenas um estudante afirmou que a metodologia não contribuiu para seu aprendizado e que "preferia aulas tradicionais" (E4). As colocações dos estudantes sobre as contribuições foram referentes à aprendizagem de conhecimentos químicos aplicados ou relacionados à legislação, ao funcionamento das macromoléculas no corpo humano, às diferentes matérias-primas utilizadas na indústria, como ilustrado nos trechos abaixo:

\section{E2: Sim. Eu tive que buscar a estrutura das moléculas em estudo, bem como suas reações características, e isso soli- dificou o meu conhecimento. \\ E3: Sim, que adoçantes não correspondem a carboidratos. Podem ser classificados com uma escala de doçura. \\ E6: Sim. Reatividade no organismo, estruturas, aplicações na indústria, etc.}

Três estudantes responderam de forma positiva, mas com algumas ressalvas quanto ao nível de aprofundamento conceitual das aprendizagens, como ilustrado na resposta do Estudante E7:

Em parte, pois nos prendeu mais nos açúcares e adoçantes do lado da legislação, de como atua no organismo, não a Química dos carboidratos em si.

Os estudantes apresentaram certa resistência à metodologia, por estarem acostumados à tradição de estudar um grande volume de conteúdos específicos. De acordo com pequisadores da área, ${ }^{1,8,15}$ o método dos EC possibilita um direcionamento aos conteúdos estruturantes da Química associados aos conteúdos procedimentais e atitudinais, como será apresentado na sequência deste artigo.

\section{Conteúdos procedimentais}

O objetivo desta categoria é analisar de que forma a metodologia de ensino auxiliou os estudantes no desenvolvimento ou aperfeiçoamento de habilidades que envolvam o "saber fazer". Os registros do Diário de Campo e o Questionário de Avaliação das Atividades Desenvolvidas foram utilizados para verificar a aptidão dos estudantes na argumentação e persuasão ao exporem seus pensamentos através da comunicação oral e escrita.

Conforme registros no Diário de Campo, no início das atividades o grupo mostrou-se bastante silencioso e pouco participativo. Alguns se conheciam, mas de forma geral a turma não apresentava integração e a timidez dos estudantes era latente no início da primeira discussão sobre o tema dos casos.

Ao iniciarem o processo de resolução dos casos, o grupo responsável pelo caso 1 não compreendeu completamente a atividade, pois apresentou uma hipótese que não indicava como poderiam reduzir o açúcar de sucos industrializados e o seu roteiro de estudos para a resolução dos casos foi apenas responder às questões norteadoras. Já o grupo responsável pelo caso 2 desenvolveu uma hipótese de trabalho na qual a redução do teor de açúcar dos sucos seria compensada com edulcorantes. O planejamento dos estudos estaria voltado à verificação da viabilidade dessa solução.

Através desses fatos é possível perceber a importância de aliar momentos de orientação para a organização das resoluções dos casos, para auxiliar os estudantes na sistematização dos conceitos envolvidos nos casos e para proposição de procedimentos mais favoráveis ao trabalho colaborativo. Todavia, parte das dificuldades enfrentadas para a resolução dos casos pode ser associada à resistência dos estudantes em executar tarefas diferentes das que estão habituados, como o trabalho em grupo, busca de refencial teórico, elaborar hipóteses, analisar resultados. Resultados similares são relatados na literatura. ${ }^{15,20,21,25}$

Na plenária, os estudantes demonstraram possuir conhecimentos sobre o tema estudado nos casos e conseguiram expressar suas ideias e apresentar resultados, porém, os grupos não formalizaram ou não sistematizaram suas resoluções. Assim, as apresentações ficaram desorganizadas. Mas isso não empobreceu a plenária. Ainda que o 
debate tenha ocorrido mais informalmente, os estudantes participaram ativamente das discussões. Praticamente todos conseguiram expor suas opiniões, demonstrando que a metodologia contribuiu para o aperfeiçoamento da habilidade de comunicação oral, de acordo com o que é afirmado na literatura. ${ }^{13,18,25,26}$

Durante as apresentações os estudantes participaram de forma significativa nas discussões e demonstraram a apropriação dos conhecimentos apresentados pelos colegas. Muitos formularam um posicionamento sobre o caso, a partir das ideias expostas pelos colegas. Dessa forma, acredita-se que o sucesso do debate se deve ao fato de que os casos despertaram o interesse dos estudantes, característica fundamental de um bom caso, segundo Herreid, ${ }^{13} \mathrm{e}$ assim houve uma construção de conhecimentos de forma coletiva. De qualquer forma, a pesquisa visava analisar as contribuições da metodologia para o desenvolvimento de habilidades necessárias aos futuros profissionais e, sendo assim, é pertinente que estes saibam organizar a apresentação de ideias e conclusões de forma sistematizada e que tenham a habilidade de analisar criticamente o que é apresentado.

Quanto aos relatórios, o material escrito pelo grupo que resolveu o Caso 1 foi bem estruturado, pois apresentava colocações e respostas às questões norteadoras de forma bem encadeada ao longo do texto. Houve preocupação do grupo na busca por informações confiáveis como legislações, documentos emitidos por órgãos oficiais como o Instituto de Defesa do Consumidor (IDEC), e artigos científicos. Esta é uma preocupação apontada tanto pelas DCNQ, ${ }^{5}$ quanto pelos Projetos Pedagógicos dos Cursos de Química ${ }^{6,7}$ (PPCs), ou seja, a formação de profissionais que saibam buscar a informação de modo que estejam sempre informados sobre os avanços da Ciência. Além disso, o contato com desafios investigativos relacionados à futura prática profissional, análise de literatura, legislações e normas técnicas pode fomentar o desenvolvimento de aptidões empreendedoras por parte dos estudantes.

O grupo que resolveu o Caso 2 entregou um texto bem consistente, com o raciocínio do grupo frente ao problema apresentado, assim como justificativa de resolução de forma coerente com suas conclusões. Porém, o relatório não apresentava fontes de informações confiáveis, como sites oficiais de órgãos reguladores, ou artigos de revistas científicas, ou de divulgação científica. Dessa forma, ao longo do relatório, o grupo desenvolveu uma linha de raciocínio na qual foi apontando os prós e os contras para as possíveis modelações de respostas, mas não alcançou uma conclusão.

Uma vez que a natureza dos casos é muito similar, esperava-se maior homogeneidade de habilidades de ordem superior relacionadas aos conteúdos procedimentais, ou seja, o saber fazer. Contudo, os estudantes responsáveis pelo Caso 1 não conseguiram elaborar hipóteses para a resolução do caso e nem identificaram questões-chave relevantes. ${ }^{8}$

Para contrapor a essa avaliação sobre o desenvolvimento das habilidades que envolviam os conteúdos procedimentais, analisou-se as afirmativas 1, 2, 5 e 6 do Questionário de Avaliação das Atividades Desenvolvidas, no qual os estudantes deveriam apontar seu grau de concordância acerca da contribuição da metodologia de ensino nos quesitos apontados. Na avaliação dos estudantes, conforme a Figura 1, o método de ensino contribuiu especialmente para a habilidade de comunicação oral (afirmativa 1) e escrita (afirmativa 2), já destacados durante as observações, pois eles tornaram-se mais participativos durante os debates e escreveram os relatórios de forma satisfatória. As habilidades de argumentação (afirmativa 5) e de persuasão (afirmativa 6) tiveram um escore menor. Durante as atividades, observou-se a dificuldade dos estudantes em tomar uma posição e defendê-la nas apresentações das resoluções dos casos.

Diversos estudos apontam que os EC favorecem o desenvolvimento de potencialidades argumentativas, ${ }^{18,22,25,26}$ entretanto, os autores salientam que algumas vezes esses argumentos não apresentam a qualidade ${ }^{18,25,26}$ ou a intensidade esperada. ${ }^{22}$ Entende-se que estimular o exercício da argumentação em situações de ensino de Química, por meio de discussões e investigações, pode contribuir para o aperfeiçoamento desta habilidade. ${ }^{18,22,25,26}$ Todavia, o grupo de sujeitos envolvidos nesta investigação vivencia atividades com estas perspectivas de forma pontual, fato que pode desfavorecer o aperfeiçoamento de tal habilidade.

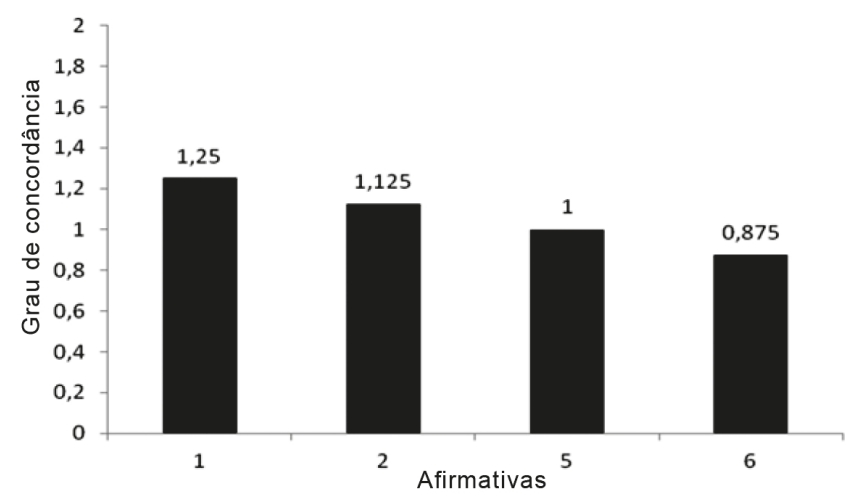

Figura 1. Grau de concordância dos estudantes frente às afirmativas elaboradas para avaliação da contribuição da metodologia para o desenvolvimento de conteúdos procedimentais. As afirmativas analisadas correspondem a: 1.Minhas habilidades de comunicação oral; 2. Minhas habilidades de comunicação escrita; 5. Minhas habilidades de argumentação diante de questionamentos; 6. Minhas habilidades de persuasão na apresentação de minhas conclusões

\section{Conteúdos atitudinais}

Nesta categoria foi examinado o "saber ser" dos estudantes, ou seja, de que forma a metodologia contribuiu para que os estudantes compreendessem a forma como eles deveriam atuar frente aos problemas impostos pelos casos, no sentido de resolvê-los de forma crítica e trabalhando em equipe. Tendo em vista que os problemas apresentados buscam se aproximar da realidade dos profissionais da Química, nesta categoria também foi avaliado de que forma as atividades propostas auxiliaram no entendimento dos conhecimentos que podem ser exigidos no exercício da profissão. Para tanto, foram analisados os registros do Diário de Campo e o Questionário de Avaliação das Atividades Desenvolvidas.

Conforme os registros do Diário de Campo, na primeira aula, quando foi apresentado o tema dos casos, detectou-se a dificuldade dos estudantes de se posicionarem frente a temas de relevância ao trabalho de um profissional químico, tendo em vista que os casos referem-se ao excesso de adição de produtos químicos diretamente relacionados aos índices de obesidade infantil no Brasil. ${ }^{41}$ Segundo pesquisadores, ${ }^{18}$ a necessidade de apresentar um posicionamento perante um problema da vida real estimula os estudantes a buscarem informações para justificar seu ponto de vista.

Neste mesmo viés, a pergunta norteadora do Caso 2 "Quais as atuais orientações dos órgãos reguladores e da legislação brasileira sobre a utilização de açúcares e adoçantes nos alimentos industrializados?" direcionava os estudantes a investigarem sobre a legislação regulamentadora que se omite quanto aos níveis de adição de açúcar em sucos industrializados. ${ }^{42}$ Desta forma, a atividade estimulou a criticidade dos discentes. ${ }^{16}$

Na elaboração das hipóteses, os estudantes enfrentaram dificuldades na organização da pesquisa que deveria ser realizada pelo grupo de forma conjunta. $\mathrm{O}$ trabalho em grupo não é apenas juntar cada um a sua parte para montar um trabalho final, mas uma tarefa colaborativa de compartilhamento e associação de ideias. ${ }^{1,9,13,10}$ Assim, ficou 
perceptível a necessidade, não apenas de oferecer atividades desse tipo, mas de estimular o entendimento do que é o trabalho em grupo, proporcionando momentos em sala de aula, para a vivência de tarefas dessa natureza. Nas aulas direcionadas para a pesquisa bibliográfica e orientação, os estudantes do grupo participaram de forma pouco satisfatória, muitos não vieram no dia da orientação e discussão com a professora. A ausência dos estudantes na aula de orientação demonstra certa imaturidade dos mesmos no direcionamento dos seus estudos, portanto, conforme relatado por Cheng, ${ }^{15}$ há a necessidade de que o professor oriente e acompanhe a execução das tarefas.

$\mathrm{Na}$ apresentação das resoluções dos casos a timidez inicial, relatada anteriormente, foi vencida e a turma mostrou-se mais entrosada e receptiva. Frente a isso, é possível afirmar que o estímulo ao debate e à troca de ideias entre os estudantes e a professora contribui não só para a apropriação de conteúdos conceituais, mas também para o desenvolvimento de conteúdos atitudinais, pois ao final das atividades os discentes estavam mais confiantes diante do desafio de apresentar suas ideias em público. Entende-se que a atividade realizada favoreceu a formação do espírito crítico dos estudantes, conforme orientam as $\mathrm{DCNQ}^{4,5}$ e os PPCs. ${ }^{6,7}$ Esse resultado pode ser evidenciado com o debate sobre a legislação, a rotulagem dos produtos, a falta de acesso à informação por parte da população quanto aos riscos e benefícios do consumo de açúcares e de edulcorantes.

No sentido de verificar a avaliação dos estudantes quanto à contribuição da metodologia para o desenvolvimento de conteúdos atitudinais, a partir do Questionário de Avaliação das Atividades Desenvolvidas, foram selecionadas as afirmativas 3, 4, 7 e 8, assim como as respostas da pergunta aberta 1 deste questionário.

Conforme a Figura 2, os estudantes avaliaram que a metodologia contribui de forma significativa para o desenvolvimento das habilidades referentes aos conteúdos atitudinais, com ênfase para a habilidade de trabalho em grupo (afirmativa 3), que obteve maior escore de grau de concordância (1,5). Esta habilidade foi destacada ao longo deste trabalho como uma das fragilidades da formação dos estudantes que precisam ser mitigadas, através do uso de metodologias de ensino que favoreçam a interação entre os sujeitos, por exemplo. Salienta-se que a afirmativa 8 apresentou um considerável grau de concordância, corroborando com a interpretação inicial sobre o desenvolvido da criatividade e da capacidade crítica no enfrentamento dos problemas apresentados pelos casos.

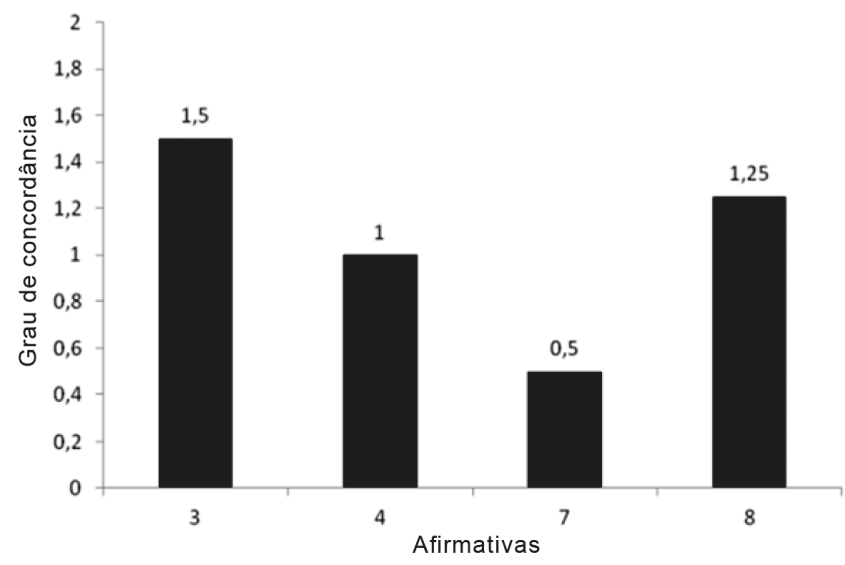

Figura 2. Grau de concordância dos estudantes frente às afirmativas elaboradas para avaliação da contribuição da metodologia de ensino no desenvolvimento de conteúdos atitudinais. As afirmativas analisadas correspondem a: 3. Minhas habilidades de realizar trabalhos em grupo; 4. Minhas habilidades de investigar soluções para resolver problemas; 7. Minha compreensão acerca dos conhecimentos que serão exigidos no meu futuro profissional; 8. Minha criatividade e criticidade frente a problemas da vida real
Alguns estudantes julgaram que não conseguiram desenvolver sua capacidade de resolução de problemas (afirmativa 4). Entende-se que como um dos grupos afirmou não conseguiu apontar uma solução e o outro grupo não conseguiu determinar uma única resposta ao problema, eles tenham apresentado essa avaliação. Todavia, o simples fato de buscar a resolução do caso, de ponderar os entraves e as dificuldades para conseguir encontrar o melhor caminho a ser apontado, pode ser considerado como um exercício que favorece o desenvolvimento desta habilidade. Como os estudantes conseguiram compreender a proposta e se dedicaram na sua execução, é possível inferir que a metodologia contribuiu para o desenvolvimento dessa habilidade..$^{24-26}$

Não foi dado um grau de concordância elevado à afirmativa 7, na qual são destacados os conhecimentos que foram desenvolvidos e que serão exigidos diretamente na profissão a ser exercida. Porém, ao responderem à questão aberta do questionário de avaliação, os estudantes destacaram a importância da metodologia no desenvolvimento desses conhecimentos. A habilidade de investigação foi destacada por quatro estudantes. Acredita-se que, se os estudantes se habituarem à atividade de resolução dos casos, poderão ficar mais confortáveis na execução das tarefas e isso também é válido para os docentes, que conforme adquirem experiência no emprego da metodologia tornam-se mais habilitados para condução das etapas da investigação. ${ }^{13,18,21}$ Dois estudantes destacaram em suas respostas que desenvolver a habilidade de trabalhar em grupo é uma característica importante no cotidiano da vida profissional. Nesses relatos, os estudantes demonstram a consciência sobre a importância da colaboração e interação entre os sujeitos para a compreensão dos conceitos científicos, assim como da natureza da construção destes conhecimentos. ${ }^{24-26}$ Quando dois estudantes indicaram que o desenvolvimento de sua capacidade de discussão com o grupo foram aspectos positivos da metodologia, também corroboraram com a ideia de construção colaborativa do conhecimento. De uma forma geral, em todas as respostas os estudantes apresentaram pontos positivos da metodologia no desenvolvimento de aspectos que julgam significativos para a atuação profissional.

\section{CONCLUSÕES}

Com o conjunto de dados analisados verificou-se que a ação formativa contribuiu para a aprendizagem de conteúdos conceituais da Química, como o estudo das estruturas dos açúcares, da sua ação como conservante, da reatividade e ação destas biomoléculas no organismo humano. Nesse sentido, as atividades contemplaram as orientações dos $\mathrm{PPCs}^{6,7}$ e das $\mathrm{DCNQ}^{5}$ quanto à sólida formação dos conhecimentos científicos. Da mesma forma, aos apontamentos da literatura sobre a necessidade de consciência quanto ao papel do químico na sociedade, ${ }^{1-3}$ ao investigarem a função dos açúcares enquanto matéria-prima da indústria de alimentos e os seus malefícios à saúde. Os estudantes também tiveram contato com a legislação da área de produção de bebidas, uma lacuna apontada na formação do químico.

Ademais, salienta-se que o diferencial dessa metodologia é o desenvolvimento dos conteúdos procedimentais e atitudinais que podem ser negligenciados por metodologias mais tradicionais. ${ }^{15}$ Dentre as Habilidade de Ordem Superior ${ }^{13}$ que foram instigadas com os EC, destaca-se o trabalho em equipe, o espírito investigativo, a criatividade, a iniciativa na busca de soluções para questões individuais e coletivas relacionadas com a Química, a capacidade de leitura e interpretação de textos científico-tecnológicos, a comunicação e defesa de proposições que envolvem a linguagem científica na forma oral e escrita.

Nessa perspectiva, constatou-se que a prática permitiu o desenvolvimento dos conteúdos procedimentais relacionados à comunicação escrita com a elaboração dos relatórios, e de comunicação oral dos estudantes, já que foi possível observar uma evolução dos mesmos, 
desde o primeiro momento em que a argumentação e defesa de ideias foram solicitadas, até a apresentação das resoluções dos casos. Assim como dos atitudinais, ainda que alguns estudantes não tenham levantado questões-chave na resolução dos problemas, os grupos conseguiram apresentar um planejamento de estratégias para solucionar os casos, mesmo que não tenham chegado a uma única ideia.

Salienta-se que as dificuldades enfrentadas para a resolução dos casos, como a elaboração de hipóteses, organização da pesquisa, trabalho em grupo e a defesa de opinião podem estar associadas à falta de experiência com atividades investigativas durante o processo de formação inicial. Sendo assim, salienta-se que a disseminação da metodologia de ensino de Estudos de Caso pode mitigar as lacunas formativas dos profissionais da Química, podendo assim contribuir para a constituição de cursos que se aproximem mais dos objetivos estabelecidos nas DCNQ. ${ }^{5}$

\section{MATERIAL SUPLEMENTAR}

Os casos produzidos e utilizados neste trabalho estão disponíveis em http://quimicanova.sbq.org.br, na forma de arquivo PDF, com acesso livre.

\section{REFERÊNCIAS}

1. Belt, S. T.; Chem. Educ. Res. Pract. 2005, 6, 166.

2. Machado, S. P.; Quim. Nova 2013, 36, 911.

3. Andrade, J. B.; Cadore, S.; Vieira, P. C.; Zucco, C.; Pinto, A. C.; Quim. Nova 2004, 27, 358.

4. Parecer CNE/CES n ${ }^{\circ} 1.303 / 01$, de 7 de dezembro de 2001. Diretrizes Curriculares Nacionais para os Cursos de Química, Brasil, 2001.

5. Resolução CNE/CES N ${ }^{\circ}$, de 11 de março de 2002. Estabelece as Diretrizes Curriculares para os cursos de Bacharelado e Licenciatura em Química.

6. UFRGS. Comissão de Graduação em Química. Projeto pedagógico do curso de bacharelado em Química da UFRGS. Porto Alegre, 2009. Disponível em http://www.iq.ufrgs.br/graduacao/images/ppedagogicos/ PPC_BACHARELADO-.pdf. Acessada em julho 2018.

7. UFRGS. Comissão de Graduação em Química. Projeto pedagógico para a Licenciatura em Química da UFRGS. Porto Alegre, 2005. Disponível em http://www.iq.ufrgs.br/graduacao/images/ppedagogicos/ LICENCIATURA-EM-QUMICA_revisao-23-05.pdf. Acessada em julho 2018.

8. Sá, L. P.; Queiroz, S. L.; Estudo de Casos no ensino de Química. Editora Átomo: Campinas, 2010.

9. Sá, L. P.; Queiroz, S. L.; Quim. Nova 2007, 30, 2035.

10. Cornely, K.; J. Chem. Educ. 1998, 75, 475.

11. Zabala, A.; A Prática Educativa: Como ensinar, Artmed: Porto Alegre, 1998.

12. Coll, C.; Marc Curricular per al' Enseyement Obligatori. Dep. de Enseñanza de la Generalitat de Cataluña: Barcelona, 1986.

13. Herreid, C. F.; J. Coll. Sci. Teach. 1994, 23, 221.

14. Herreid, C. F.; J. Coll. Sci. Teach. 2013, 90, 256.

15. Cheng, V. K. W.; J. Chem. Educ. 1995, 72, 525.

16. Sá, L. P.; Francisco, C. A.; Queiroz, S. L.; Quim. Nova 2007, 30, 731.

17. Pierini, M. F.; Rocha, N. C.; Silva Filho, M. V.; Castro, H. C.; Lopes, R. M.; Quim. Nova Esc. 2015, 37, 112.
18. Souza, N. S.; Cabral, P. F. O.; Queiroz, S. L.; Quim. Nova Esc. 2015, 37, 95.

19. Broeitti, F. C. D.; Quim. Nova Esc. 2017, 39, 367.

20. Pinheiro, A. N.; Medeiros, E. L.; Oliveira, A. C.; Quim. Nova 2010, 33, 1996.

21. Massena, E. P.; Guzzi Filho, N. J.; Sá, L. P.; Quim. Nova 2013, 36, 1066.

22. Cabral, P. F. O.; Souza; N. S.; Queiroz, S. L.; Quim. Nova 2017, 40, 1121.

23. Oliveira, J. R. S.; Rev. Ensaio 2010, 12, 279.

24. Francisco, W.; Revista Electrónica de Enseñanza de las Ciencias 2013 , $12,419$.

25. Velloso, A. M. S.; Sá, L. P.; Motheo, A. J.; Queiroz, S. L.; Revista Electrónica de Enseñanza de las Ciencias 2009, 8, 593.

26. Sá, L. P.; Kasseboehmer, A. C.; Queiroz, S. L.; Educ. Quím. 2013, 24, 522.

27. Merriam, S. B.; Qualitative Research and Case Study Applications in Education. Allyn and Bacon: San Francisco, 1998.

28. Bogdan, R.; Biklen, S.; Investigação Qualitativa em Educação. Editora Porto: Porto, 1994.

29. Lüdke, M.; André, M. E. D. A.; Pesquisa em educação: Abordagens Qualitativas, E. P. U.: São Paulo, 1986.

30. Günther, H.; Como Elaborar um Questionário, Laboratório de Psicologia Ambiental UnB: Brasília, 2003.

31. Goi, M. E. J.; Dissertação de Mestrado, Universidade Luterana do Brasil, Brasil, 2004.

32. Sá, L. P.; Dissertação do Mestrado, Universidade de São Paulo, Brasil, 2006.

33. Nelson, D. L.; Cox, M. M.; Princípios de bioquímica de Lehninger. Artmed: Porto Alegre, 2011.

34. http://butane.chem.uiuc.edu/pshapley/genchem2/b4/index.html, acessada em julho 2018.

35. Ministério da Agricultura, Pecuária e Abastecimento. Decreto $n^{\circ} 2.314$, de 04 de setembro de 1997. Regulamenta a Lei ${ }^{\circ}$ 8.918, de 14 de julho de 1994, que dispõe sobre a padronização, a classificação, o registro, a inspeção, a produção e a fiscalização de bebidas. Brasília, 1997.

36. Ministério da Agricultura, Pecuária e Abastecimento. Decreto $n^{o}$ 8592, de 16 de dezembro de 2015. Altera dispositivos do regulamento aprovado pelo Decreto $\mathrm{n}^{\circ} 2.314$, de 4 de setembro de 1997 , que dispõe sobre a padronização, a classificação, o registro, a inspeção, a produção e a fiscalização de bebidas, Brasília, 2015.

37. Santos, I. A.; Dissertação de Mestrado, Universidade Federal de Santa Catarina, Brasil, 2012.

38. Erlanson-Albertsson, C.; Basic Clin. Pharmacol. Toxicol. 2005, 97, 61.

39. Bruyère, O.; Ahmed, S. H.; Atlan, C.; Belegaud, J.; Bortolotti, M.; Canivenc-Lavier, M.; Charrière, S.; Girardet; J.; Houdart, S.; Kalonji, E.; Nadaud, P.; Rajas, F.; Slama, G.; Margaritis, I.; Archives of Public Health 2015, 73, 41.

40. Agência Nacional de Vigilância Sanitária, Informe Técnico $n^{\circ}$. 40, de 2 de junho de 2009: Esclarecimentos sobre o uso do edulcorante ciclamato em alimentos, Brasília, 2009. Disponível em: http://portal.anvisa.gov. br/informacoes-tecnicas13/-/asset_publisher/FXrpx9qY7FbU/content/ informe-tecnico-n-40-de-2-de-junho-de-2009/33916. Acessado em julho 2018.

41. Feferbaum, R.; Abreu, L.; Leone, C.; BMC Public Health 2012, 12 , 1005.

42. Ferrarezi, A. C.; Santos, K. O.; Monteiro, M.; Rev. Nutr. 2010, 23, 4. 